\title{
Mobilização comunitária e vigilância em saúde no controle de vetores, estratégias da promoção da saúde: conquistas e desafios
}

\section{Communitarian mobilization and health vigilance on vectors control, health strategies: achievements and chalenges.}

João Carlos de Oliveira', Samuel do Carmo Lima²

Este texto apresenta algumas reflexões sobre as contribuições da mobilização comunitária, no controle dos Aedes e na prevenção da dengue, como estratégias de promoção da saúde.

Tradicionalmente, a dengue tem uma relação unidirecional com o Aedes aegypti. Isto é uma verdade, até porque os índices de notificações, mortes, recursos financeiros e investimentos direcionados para este vetor são significativos. Por outro lado, os estudos sobre o Aedes albopictus parece que tem ficado em segundo plano, no que se refere ao seu comportamento bioecológico na natureza, bem como nos ambientes urbanizados, o que permite uma série de consequências para a sociedade, principalmente em epidemias, confundindo-o com outros arbovírus, o que pode comprometer a saúde da coletividade.

Também merece atenção, o fato de que o Aedes albopictus pode ter uma correlação com o Vírus do Nilo Ocidental (VNO) (que acomete as pessoas com riscos de encefalite) pela facilidade com que algumas aves migratórias, consideradas reservatórias desse arbovírus, adentram o nosso país.
Várias espécies de mosquitos revelaram potenciais vetores deste arbovírus, figurando mais uma vez o Aedes albopictus e o Culex quinquefasciatus, mosquitos que, em áreas urbanas, podem transmitir filariose e tornamse incômodo, devido à atividade hematófaga.

As atividades sempre estiveram relacionadas com o CAP - Conhecimentos, Atitudes e Procedimentos sobre a doença (modo de transmissão, quadro clínico e tratamento), o vetor (hábitos e criadouros) e medidas de Promoção da Saúde. Entendemos que a comunidade não está apartada das demais relações socioambientais, que compõem os diferentes territórios dos saberes e fazeres, dos sujeitos, que se deram ao longo do tempo e em todos os lugares.

Por isso, nossa ideia da promoção da saúde assenta-se na concepção defendida pelo linguísta russo Mikhail Bakthin, que propõe o conceito de "polifonia", ou seja, que a comunicação não deve ser vista apenas como transmissão de informações, mas sim como um processo de produção e ressignificado de sentidos sociais.

Por outro lado, entendemos, e hoje mais ainda, que a mobilização comunitária deveria

1. Doutor em Geografia pela Universidade Federal de Uberlândia, professor na Escola Técnica de Saúde da Universidade Federal de Uberlândia / Doctor of Geography at the Federal University of Uberlândia, professor at Technical School of Health at the Federal University of Uberlândia. E-mail: oliveirajota@estes.ufu.br.

2. Doutor em Geografia pela Universidade de São Paulo, professor no Instituto de Geografia da Universidade Federal de Uberlândia, coordenador do Laboratório de Geografia Médica e Vigilância em Saúde / Doctor of Geography at the University of São Paulo, professor at Geography Institute at the Federal University of Uberlândia, Laboratório de Geografia Médica e Vigilância em Saúde coordinator. E-mail: samuel@ufu.br. 
e deve ser entendida e praticada enquanto Estratégia da Promoção da Saúde, levando em consideração o que destaca a Carta de Ottawa (1986): 1) o estabelecimento de políticas públicas saudáveis, 2) criação de ambientes e entornos saudáveis, 3) empoderamento e ação comunitária, 4) desenvolvimento de habilidades pessoais e 5) reorientação dos serviços de saúde.

Nos últimos anos, as condições de saúde da população têm melhorado de forma contínua e sistemática, graças a um conjunto de fatores ambientais (estes além do químico, físico e biológico) associados aos avanços técnicos na área da saúde pública, da infraestrutura das engenharias e da medicina. Entretanto, estes avanços técnicos, em especial nas cidades, passaram a serem focos de diversos estudos, com atenção para a saúde ambiental.

O caráter inovador nesta abordagem, integrando saúde/ambiente, tem reflexo no paradigma Promoção da Saúde. De acordo com a Organização Pan Americana de Saúde (OPAS, 2002), uma experiência de município e comunidade saudável começa com o desenvolvimento e/ou o fortalecimento de uma parceria entre autoridades locais, líderes da comunidade e representantes dos vários setores públicos e privados, no sentido de posicionar a saúde e a melhoria da qualidade da vida na agenda política e como uma parte central do planejamento do desenvolvimento municipal.

Neste universo de preocupações, considera-se a dengue como sendo uma das principais arboviroses ${ }^{3}$ de impactos significativos nas regiões tropicais e subtropicais, em função de algumas condições ambientais (ㄷ e mm) e dos comportamentos das pessoas em manter, de forma inadequada, criadouros e água parada em seus ambientes.

Nasáreasurbanas, ressalta-seaimportância da espécie introduzida, o Aedes aegypti. Além de seu potencial na veiculação do vírus da febre amarela no ambiente urbano, essa espécie, a partir da década de 1980, passou a veicular os vírus da dengue no Brasil. É, sem dúvida, o mosquito mais combatido no país e aquele para o qual se disponibiliza maiores recursos para controle. Entretanto, a dengue tornouse endêmica, fato que demonstra o fracasso nas formas de combate e práticas aos vetores.

$\mathrm{Na}$ verdade, há necessidade de uma linguagem comunicativa mais adequada ao cotidiano da população, como forma de ampliação de determinadas informações básicas e necessárias para melhor compreensão, interação e integração com as pessoas, sobre os saberes e os fazeres nos cuidados com o ambiente, que muitas vezes não depende das pessoas, em si, pois há uma correlação direta com as condições ambientais (período chuvoso, com pequenos veranicos).

Normalmente, as formas para mudar as atitudes das pessoas são campanhas que, normalmente, ocorrem em situações de surtos, preferencialmente no verão, com a aplicação e controle químico - Ultra Baixo Volume (UBV). Já está consolidado que este modelo de vigilância em saúde não surte efeito prolongado, não envolve as comunidades atingidas e muito menos tem um modelo de comunicação polifônica, no sentido defendido por Bakhtin.

No Brasil, as epidemias de dengue se sucedem a cada ano, ora em uma região, ora em outra; ora em uma cidade, ora em

3. Segundo Biddle (1998, p. 41), “a palavra 'arbovírus' tem sua origem na expressão inglesa arthropodborne vírus (vírus transportados por artrópodes), que significa vírus que se propagam dentro de insetos e outros artrópodes e que nos infectam quando somos picados. Existem mais de 520 tipos conhecidos de arbovírus, dos quais cerca de cem provocam sintoma aparente. Mas a encefalite, a febre amarela, a febre da dengue e uma verdadeira coleção de exóticas febres tropicais [...] conferem a estes micróbios uma má reputação merecida [...]. As pessoas geralmente são hospedeiros "sem saída" para os arbovírus [...]. Os pássaros são hospedeiros muito importantes do que nós para os arbovírus. As grandes exceções são a febre amarela, a dengue, e a febre chikungunya, para as quais servimos como elo vital em seu ciclo de vida". 
outra, em função de condições climáticas e, principalmente, do estilo de vida urbano atual e do nível de (des)organização das cidades, com falta de infraestrutura e vulnerabilidade socioambiental das populações, principalmente nas periferias, onde se torna mais grave pelo menoracesso da populaçãoaosserviçosdesaúde.

Ainda que entre os fatores determinantes da doença haja uma componente climática, de modo que a maioria dos casos ocorra durante o verão, nos meses de maior precipitação atmosférica, não se pode imputar ao clima a causa da doença, nem mesmo ao mosquito, como aparece nas campanhas de prevenção veiculadas na televisão. Todo processo saúde-doença é multicausado.

Temos epidemias anuais de dengue porque as campanhas de prevenção estão seguindo a mesma estratégia baseadas nas ideias higienistas do século XIX dezenove que notabilizaram Osvaldo Cruz e Emilio Ribas quando combatiam o Aedes aegypti e a Febre Amarela no Rio de Janeiro e em São Paulo, no início do século XX. Parece até uma ação de guerra e é isso que sugerem as palavras campanha e combate. Usamos um exército de combatentes, os agentes de endemias, que saem equipados para a batalha todos os dias, com a missão de destruir larvas e matar mosquitos; e, se estamos em guerra contra o mosquito, então, estamos perdendo essa guerra, não por falta de recursos financeiros, mas por estratégias equivocadas.

Com relação à dengue, é de fundamental importância que se estabeleça um novo modelo de vigilância, baseado na Promoção da Saúde, considerando situações de saúde nos territórios da vida cotidiana e do trabalho dos grupos sociais, sempre considerando na medida do possível as relações interculturais.

Entretanto, outro modelo de vigilância em saúde é possível, ancorado nos princípios da promoção da saúde, que reconhece que o processo saúde-doença está fortemente determinado pelas condições de vida e trabalho dos indivíduos e coletividades, e que as intervenções do poder público devem ser estabelecidas com políticas públicas intersetoriais, mobilização social e empoderamento das comunidades para atuar sobre os determinantes sociais da saúde. Também, não podemos nos esquecer de que, em muitos casos, ausência de infraestrutura urbana, ou infraestrutura precária, em especial a limpeza urbana e o abastecimento regular de água limpa e potável, podem significar, também, condições precárias de saúde.

O primeiro nível de mobilização dos indivíduos e coletividades se faz com informação. A comunicação social dos municípios deve ir além do óbvio, só informando não se garante que água parada evita a dengue. É preciso mostrar os números exatos da infestação do Aedes aegypti e dos casos de dengue na cidade e nos bairros. É preciso realizar reuniões nas escolas, nas associações de bairro, nas igrejas para empoderar a comunidade para o enfrentamento dos problemas de saúde.

O poder público tem tentado sozinho controlar os Aedes e combater a dengue. É preciso chamar a sociedade para dividir com ele essa responsabilidade. Nesse sentido é necessário realizar, antes de tudo, uma mobilização social, num pacto pela vida, com estratégia de Promoção da Saúde, para estabelecer um processo político permanente de interação com a sociedade e evitar medidas imediatistas e/ou fragmentadas, que são tomadas somente nos momentos de epidemia.

Para nossa pesquisa de doutorado, experimentamos a ideia da mobilização comunitária como estratégia de promoção da saúde, no controle dos Aedes e na prevenção da dengue no Distrito de Martinésia, Uberlândia (MG). Para tanto, duas frentes foram significativas e relevantes, sendo, uma delas, a instalação e o monitoramento de armadilhas artificiais -denominadas de ovitrampas - e, a outra, a participação de 
uma equipe de estudantes/ protagonistas denominados "Agentes Ambientais Mirins".

Com as estratégias de Promoção da Saúde realizadas pelos Agentes Ambientais Mirins, a partir da mobilização comunitária, construímos algumas relações a partir de quatro categorias, a saber: (1) atividades de (re)conhecimento das realidades vividas pelos sujeitos, (2) atividades de educação e saúde, (3) atividades de mobilização comunitária e (4) práticas de vigilância ambiental e epidemiológica. Nas atividades de reconhecimento das realidades do Distrito de Martinésia, foi de fundamental importância o contato com algumas lideranças, estendidas para a maioria das pessoas, avaliando o grau de participação dos indivíduos no seu grupo social, em relação ao controle dos vetores da dengue e, consequentemente, a prevenção da doença, assim como a situação ambiental das moradias e dos quintais; que nos ofereceram, a cada dia, novas informações absolutamente relevantes para a compreensão da percepção, representação e ressignificação do que tinham e passaram a ter diante do problema.

As atividades de educação e saúde na comunidade ou fora do Distrito significaram mais do que transmitir informação sobre a dengue e seus vetores. Muitas vezes, não se admite que a população não tenha informações sobre a dengue e sobre a forma de reprodução do vetor. As campanhas de informação e comunicação nas diferentes mídias já cumpriram, em parte, esse papel importante de levar esclarecimento à população. Entretanto, só esclarecimento não produz a ação, o moverse para a participação com o seu grupo social.

Por isso, a educação não pode ser somente informativa, deve ser formativa, construtiva e ressignificativa, o tempo todo e em todos os lugares. Alguns autores dizem que educação é comunicar, ou que comunicar bem educa. Pode-se dizer, ainda, que educação é mais do que isso, principalmente quando a comunicação é dialógica, ou seja, aquela que considera que o outro também comunica, em um processo dialético, tal qual aponta-nos Paulo Freire (1980; 1987): "ninguém educa ninguém, os homens se educam entre si, mediatizados pelo mundo".

Durante o tempo da pesquisa (20102011)4, estabeleceu-se entre os pesquisadores (Agentes Ambientais Mirins) e a população, elos de confianças, de caminhadas juntas, para o mesmo fim, qual seja, o monitoramento e o controle dos Aedes e a prevenção contra a dengue. Sem o pacto de empatia entre os Agentes Ambientais Mirins e a comunidade, incluindo outros segmentos sociais que trabalham nos programas de controle da dengue não teria sido possível controlar o vetor, havendo de se repetir, a cada ano, as epidemias, tal como vimos na atualidade.

Este elo facilitou, ainda, o entendimento da comunidade sobre a importância de cuidar mais e melhor do nosso ambiente, principalmente a partir de parcerias de responsabilidade individual e coletiva no saneamento ambiental das casas e dos quintais, e na eliminação dos criadouros dos vetores da dengue.

Os princípios da Promoção da Saúde devem ser levados ao exercício na comunidade, valorizando as identidades individuais, com dignidade, ética e responsabilidade, além da solidariedade e sentimento de pertencimento a uma coletividade. Somente assim, poderemos ter uma sociedade que busque a saúde coletiva e as políticas públicas de saúde enquanto possibilidades de um ambiente saudável para uma maioria das pessoas.

4. A eficácia da mobilização comunitária ocorreu, principalmente, pela participação da população. Durante o tempo da pesquisa (2010-2011) não ocorreu, oficialmente, nenhum caso de dengue no Distrito pesquisado. Isto parece significativo se considerarmos que durante esse tempo, a cidade de Uberlândia, sede município, sofreu com epidemias de dengue. 